\title{
Obesity Prevalence and Physical Fitness in School-aged Children
}

\author{
Nurten Dinç*, Pınar Güzel, Selhan Özbey, Tolga Beşikçi, Sinan Seyhan, Naci Kalkan, Gülay Gezer
}

Faculty of Sports Sciences, Manisa Celal Bayar University, Turkey

Copyright $\bigcirc 2019$ by authors, all rights reserved. Authors agree that this article remains permanently open access under the terms of the Creative Commons Attribution License 4.0 International License

\begin{abstract}
The purpose of this study is to determine the overweight and obesity prevalence among students studying in primary school by ages and to reveal the relation with physical activity. 1946 students aged between 7 and 11 and receiving primary education in a district of Manisa province have participated in this study. There are 885 female students and 1061 male students. Height measurements, body composition measurements, vertical jump test and $30 \mathrm{mt}$ tests of the participants were performed respectively. SPSS 22 program was used for statistical analysis. Frequency distributions and percentage values were presented in statistical notations. Pearson correlation analysis was performed in data analysis. In conclusion, it is observed that $12 \%$ of female students are overweight, $9.5 \%$ are obese and $21.5 \%$ are both overweight and obese. $8.8 \%$ of male students are overweight, $11.3 \%$ are obese and $20.1 \%$ are both overweight and obese. There is also a statistically correlation between obesity and age and parameters of physical fitness. In order to reduce the prevalence of overweight and obesity in children, school and community-based programs must be planned to encourage children to do physical activity and exercise and to prefer low calorie intake. The content and importance of these programs should be made applicable by parents and local governments.
\end{abstract}

Keywords Obesity, Overweight, Physical Fitness, School-aged Children

\section{Introduction}

The prevalence of overweight and obesity among children increases rapidly and leads to serious health problems worldwide. This affects both developed and developing countries. While overweight and fatness is defined as "excessive fat accumulation" $[1,2]$, it results in a balance of positive energy [3]. Obesity develops when there is a discrepancy between energy intake and energy production [2]. The obesity that occurs in childhood increases the risk of obesity in adulthood and the period of obesity in childhood increases the risk of developing chronic diseases during adulthood [4]. Potential risk factors for obesity in early life include genetic, physical, lifestyle and environmental conditions [5]. According to the results of the research, it is emphasized that obesity has a significant effect on the risk factors for development of cardiovascular disease in children and adolescents and the development of atherosclerosis in adults and it is important to take precautions in the early life [6]. Type 2 diabetes also causes a number of health problems such as hypertension, some types of cancer and gallbladder diseases, musculoskeletal problems, and skin problems. Especially the possibility of developing diabetes and hypertension increases sharply with the increase of fatness in the body. This disease, which is confined to older adults, also affects obese children in the period before puberty. According to World Health Organization data, about $85 \%$ of people with diabetes are type 2 and $90 \%$ of them are obese or overweight [1].

Changeable risk factors for obesity in childhood include gestational diabetes, high levels of watching television, low levels of physical activity, ineffectiveness of parents and consuming high levels of dietary fat, carbohydrate and sugary drinks. Lack of physical activity is suggested as an important factor in childhood obesity. Increased energy, low energy consumption and low physical activity are one of the factors that cause an increase in the body mass index in children [1].

The most commonly used measurement to identify obesity is body mass index (BMI) (weight / height ${ }^{2}, \mathrm{~kg} /$ $\mathrm{m}^{2}$ ) [7]. Obesity diagnosis in children is evaluated with percentile curves by considering age and gender factors as different from the adults. Children and adolescents with BMI above 85 percentile are defined as overweight and children and adolescents with BMI above 95 percentile are defined as obese $[8,9]$. The possibility of a permanent obesity is high in children with BMI above 95 percentile and it is related to morbidity $[10,11]$. 
The negative effect of obesity on health and quality of life is emphasized in literature. Limited and school-based programs that combine the promotion of healthy eating habits and physical activity show that it is possible to prevent obesity in children and adolescents [12]. In this regard, the purpose of this study is to determine the overweight and obesity prevalence among primary school students by ages and to reveal the relation with physical fitness.

\section{Materials and Methods}

1946 students aged between 7 and 11 and receiving primary education in a district of Manisa province have participated in this study. There are 885 female students and 1061 male students. The families of all participants were informed by the working team and permission of parents on voluntary participation was taken. All participants were asked for health reports before participating in the study. The students without any health problems participated in the study.

Height measurements, body composition measurements and vertical jump tests of the participants were performed respectively.

Body composition measurement: Body composition measurements were performed in the early hours with Tanita MC 780 MA. With this measurement, participants' weight, body mass index, body fat ratio, lean muscle mass were determined. Participants were advised not to make any liquid consumption before measurement.

Percentile evaluation: Obesity diagnosis in children is evaluated with percentile curves by considering age and gender factors as different from the adults.

Table 1. Obesity classification

\begin{tabular}{|c|c|}
\hline Below 5 percentile & Thin \\
\hline 5 percentile -84 percentile & $\begin{array}{c}\text { Normal or Healthy } \\
\text { Weight }\end{array}$ \\
\hline $\begin{array}{c}\text { Above } 85 \text { percentile and below } 94 \\
\text { percentile }\end{array}$ & Overweight \\
\hline Above 95 percentile & Obesity \\
\hline
\end{tabular}

Vertical Jump Test: In front of a wall-hung platform, the student tried to jump as high as possible. Before the test, the student's normal arm length was determined in front of the platform to be tested. The difference between the student's jump distance and arm length was determined following the test and vertical jump distance was recorded in "cm". The test was repeated twice on the participants and the best result was recorded [13].

30 Meters Sprint: Participants showed sprint performance in a rubber covered area. Participants' sprint duration (Brower Timing Systems, Draper, UT) was recorded using a photocell. Participants did two times 30 metres test and the best result had taken.

Statistical Analysis: SPSS 22 program was used for statistical analysis. Frequency distributions and percentage values were indicated in statistical notations. Pearson correlation analysis was performed in data analysis. The significance limit used during the study was $\mathrm{p}<0.05$.

\section{Results}

In Table 2, overweight and obesity percentages of the participant children are presented by taking into account the variables of BMI values, age and gender and by classifying them according to percentile curves.

Table 2. Overweight and obesity percentages by gender and age

\begin{tabular}{|c|c|c|c|}
\hline Age & Gender & Overweight & Obese \\
\hline 7 age & Girls & 9.1 & 13.6 \\
\hline & Boys & 1.9 & 13.1 \\
\hline 8 age & Girls & 13 & 8.7 \\
\hline & Boys & 9.1 & 10.6 \\
\hline 9 age & Girls & 12.5 & 9.6 \\
\hline & Boys & 9.0 & 15.8 \\
\hline 10 age & Girls & 12.9 & 10.2 \\
\hline & Boys & 10.9 & 8.7 \\
\hline 11 age & Girls & 8.7 & 5.8 \\
\hline & Boys & 8.4 & 3.6 \\
\hline
\end{tabular}

According to Table 2, the highest obesity level in females is observed in the ages of 7 and 10 while the highest obesity level in males is observed in the ages of 9 and 10 .

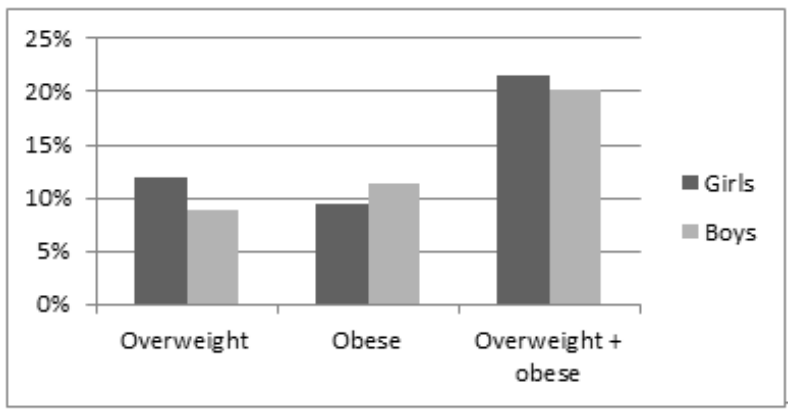

Figure 1. Overweight and obesity percentages of females and males at the age range of 7-10.

According to Figure 1, 12\% of females are observed to be overweight, $9.5 \%$ are obese and $21.5 \%$ overweight and obese, while $8.8 \%$ of males are seen to be overweight, $11.3 \%$ are obese and $20.1 \%$ are overweight and obese.

The relation between BMI and physical fitness is indicated in Table 3. 
Table 3. The relation between BMI and parameters of physical fitness

\begin{tabular}{|c|c|c|c|c|c|}
\hline & & Age & Gender & Vertical Jump & 30 meters \\
\hline \multirow{3}{*}{ BMI } & Pearson Correlation &, 192 &,- 023 &,- 073 &, 100 \\
\cline { 2 - 6 } & Sig. (2-tailed) &, $000 *$ &, 320 &, $001 *$ &, $000 *$ \\
\cline { 2 - 6 } & $\mathrm{N}$ & 1966 & 1966 & 1966 & 1966 \\
\hline
\end{tabular}

$*_{\mathrm{p}}<0.05$

As per Table 3, between age and BMI positive statistically relation and between BMI and physical fitness parameters there were a statistically negative relation had occurred.

\section{Discussion}

The risk of obesity in school-aged children is one of the determinants of the health-related lifestyle and the initiator of many problems in the future life of the child [14]. As a result of the study, the overweight rate in boys and girls within the age range of $7-11$ was found to be $8.8 \%$ and $12 \%$ respectively. Looking at the obesity levels for the age group of $7-11$, these are $11.3 \%$ and $9.5 \%$ for boys and girls, respectively. The rate of overweight + obesity in girls is $21.5 \%$ and $20.1 \%$ in boys. It has been determined in the study performed in Turkey in 2010 that the overweight rate for the age range of $6-18$ is $14.3 \%$, the frequency of obesity is $8.2 \%(9.1 \%$ in boys and $7.3 \%$ in girls $)$ and the rate of overweight + obesity is $22.5 \%$ [15]. Analyzing the data of 2016 in our study it is clearly seen that the rate of overweight has decreased while the obesity rate has increased within 6 years.

According to the Investigation Report of "Surveillance on Growth Monitoring in School Aged Children in Turkey" (2009), the overweight percentages in Turkey are 15.3 for the age of $7,14.4$ for the age of $8,14.1$ for the age of 9 and 14.5 for the age of 10 . The obesity percentages are 5.8 for the age of 7,6.1 for the age of 8, 7.7 for the age of 9 and 6.9 for the age of 10 . The total overweight and obese percentages are 21.1 for the age of 7, 20.5 for the age of 8 , 21.8 for the age of 9 and 21.4 for the age of 10 [16]. In our study, the overweight percentages are 5.5 for the age of 7 , 11.05 for the age of $8,10.75$ for the age of 9 and 11.9 for the age of 10 and 8.55 for the age of 11 . The obesity percentages are 13.35 for the age of 7,9.65 for the age of 8 , 12.7 for the age of $9,9.45$ for the age of 10 and 4.7 for the age of 11 . As a result of this study conducted according to ages, it is seen that overweight percentages decreased and obesity rates increased in every age group in 2016.

According to the National Health and Nutrition Examination Survey (NHANES), obesity prevalence has increased from $6 \%$ to $10.7 \%$ in children (aged 6-11) and from $4.8 \%$ to $10.7 \%$ in adolescents (aged 12-17) in 10 years (1976-1980 / 1988-1991) [17].

Examining the studies performed in other countries, it has been established in the study performed in Brazil in that $17.3 \%$ are overweight $(18.0 \%$ of women and $15.3 \%$ of men) and $15.0 \%$ are obese (12.5 of women and $18.9 \%$ of men). Overweight and obesity percentages in Brazil are observed to be higher than the percentages in our study [18].

Shields (2006) has found in his study that $12 \%$ of the children at the age range of 2-17 and living in Canada in $1978-79$ are overweight and $3 \%$ of them are obese and $15 \%$ are overweight + obese. The rate of overweight and obesity has been reported to increase as of 2004 (18\% for overweight and 8\% for obesity) [19]. Kleiser et al. (2009) have expressed that the prevalence of obesity in Germany doubled compared to the early 1990s [5]. In the study of Reily (1999) which addresses overweight and obesity conditions by ages, overweight-obesity percentages in men have been ascertained as follows; $25.7 \%$ for the age of 7 , $24.3 \%-11.8 \%$ for the age of $8,25.2 \%-13 \%$ for the age of $9,23 \%-9.6 \%$ for the age of 10 and $27.8 \%-13.9 \%$ for the age of 11 . The overweight-obesity percentages in women are as follows; $17.6 \%-11.8 \%$ for the age of $7,20.7 \%-$ $13.2 \%$ for the age of $8,19 \%-9.5 \%$ for the age of $9,23.9 \%$ $-11.1 \%$ for the age of 10 and $23.9 \%-11.1 \%$ for the age of 11 [9]. When the percentages obtained from the results of the research are compared with the percentages observed in our study, it is seen that especially the overweight rates are high. In conclusion, obesity is a worldwide problem and the rate of obesity is gradually increasing.

Age is considered to be an important factor in being overweight. Obesity that starts early in life continues until adulthood and increases the risk of obesity-related morbidity in following stages of life [20]. Lipid abnormalities between children and adolescents are associated with the risk of insulin resistance and hypertension afterwards and play an important role in the development of heart disease. In the study of Nemet et al. (2005), significant decreases have been found in serum cholesterol and LDL cholesterol levels in the activity group [21]. In addition, Figueroa-colon et all (1997) have found that systolic and diastolic blood pressure is significantly higher in obese children compared to non-obese children [22].

Potential risk factors for obesity in early stages of life include genetic, physical, lifestyle and environmental conditions. Furthermore, increased calorie intake and reduced energy expenditure and sedentary lifestyle (e.g. watching television, computer games, mobile phone) play a major role in the mechanisms responsible for the prevalence of obesity [21, 23]. For this reason, both diet 
and physical activity parameters have been emphasized as appropriate interventions for prevention of obesity. Physical activity is suggested to play a role not only in the development of childhood obesity, but also in many health problems, lifestyle models and psycho-social welfare [20].

Today, the prevalence of television, computer and video games has increased in children and adolescents. Andersen et al. (1998) have reported that children who watch television more and participate in physical activity less have higher BMI values [24]. According to Eliakim (2002), significant weight loss, decrease in BMI and watching TV and ensuring improvement can be observed in obese children and adolescents with a 3-month nutrition-behavior-exercise intervention [23]. A statistically significant relation has been found between BMI and physical fitness in our study. Thus, community-based interventions aiming physical activity, low calorie intake, balanced nutrition and eating behavior should be created in order to reduce the prevalence of obesity in children (Obesity in children. Part 2: 2008)

\section{Conclusions}

In our study and literature, obesity prevalence in children is observed to be increasing and it is a worldwide health problem. The negative relation between obesity and physical activity has also emerged in our study. The importance of school and community-based multidisciplinary programs is emphasized in order to reduce the prevalence of overweight and obesity in children. By encouraging children for physical activity, suitable environments should be created for them and care must be provided to nutrition. For this purpose, various seminars should be given about the benefits of physical activity and how to have a proper and balanced nutrition to families and children in schools. Official institutions and relevant organizations must perform long-term physical activity works regarding children's healthy life and children should be encouraged for these programs.

\section{REFERENCES}

[1] Obesity: preventing and managing the global epidemic. Report of a WHO consultation. World Health Organ Tech Rep Ser. 2000; 894:i-xii, 1-253.

[2] Wabitsch, M. (2000). 0verweight and obesity in European children: definition and diagnostic procedures, risk factors and consequences for later health outcome. European Journal of Pediatrics. 159(1), 8-9.

[3] Rosenbaum, M., and Leibel, R.L. (1998). The Physiology of Body Weight Regulation: Relevance to the Etiology of Obesity in Children. Pediatrics, 101(3 Pt 2), 525-239.

[4] Takahashi, E., Yoshida, K., Sugimori, H., Miyakawa, M.,
Izuno, T., Yamagami, T., and Kagamimori, S. (1999). Influence factors on the development of obesity in 3 -year-old children based on the yam study. Preventive Medicine, 28(3): 293-296.

[5] Kleiser, C., Rosario, A.S., Mensink, G.B., Prinz-Langenohl, R., Kurth, B.M. (2009).Potential determinants of obesity among children and adolescents in Germany: results from the cross-sectional KiGGS Study. BMC Public Health. Feb 2;9:46. doi: 10.1186/1471-2458-9-46.

[6] Bridger T. (2009). Childhood obesity and cardiovascular disease. Paediatrics Health, 14(3), 177-182.

[7] Kosti, R.I., Panagiotakos, D.B. (2006). The epidemic of obesity in children and adolescents in the world. Central European Journal of Public Health, 14(4), 151-159.

[8] Dietz, W.H., Bellizzi, M.C. (1999). Introduction: the use of body mass index to assess obesity in children. The American Journal of Clinical Nutrition, 70(1), 123-125.

[9] Reilly, J J., Dorosty, A.R. (1999) Epidemic of obesity in UK children. The Lancet, 27; 354(9193), 1874-1875.

[10] Daniels S.R. (2009). Complications of obesity in children and adolescents. International Journal of Obesity, 33, 60-65.

[11] Ebbeling, C.B., Pawlak, D.B., Ludwig, D.S. (2002). Childhood obesity: public-health crisis, common sense cure. Lancet. 10; 360(9331), 473-482.

[12] Flodmark, CE., Marcus C. and Britton M. (2006). Interventions to prevent obesity in children and adolescents: a systematic literature review. International Journal of Obesity, 30(4), 579-589.

[13] Tamer, K. Sporda Fiziksel (2000) Fizyolojik Performansın Ölçülmesi ve Değerlendirilmesi, Bağırgan Yayımevi Ankara, s. 131-141.

[14] Jang, M., Grey, M., Sadler, L., Jeon, S., Nam, S., Song, H.J., Whittemore, R. (2018). Obesity-risk behaviours and their associations with body mass index (BMI) in Korean American children. Journal of Clinical Nursing, 27(17-18), 3408-3417.

[15] Türkiye beslenme ve sağlık araştırması (TBSA) 2010, Saha uygulaması el kitab1, Ankara, Ocak 2010.

[16] Sağlık Bakanlığı, Hacettepe Üniversitesi Sağlık Bilimleri Fakültesi Beslenme ve Diyetetik Bölümü, T.C. Milli Eğitim Bakanlığı. (2011). Türkiye'de Okul Çağı Çocuklarında (6-10 Yaş Grubu) Büyümenin İzlenmesi Projesi Araștırma Raporu (TOÇBİ). Kuban Matbaacılık, Sağlık Bakanlığı Yayın, Ankara.

[17] Trost, S.G., Kerr, L.M., Ward, D.S., Pate, R.R. (2001). Physical activity and determinants of physical activity in obese and non-obese children. International Journal of Obesity, 25(6), 822-829.

[18] Silva, A.P.D., Feilbelmann, T.C.M., Silva, D.C., Palhares, H.M.C., Scatena, L.M., Resende, E.A.M.R., Fátima Borges, M. (2001). Prevalence of overweight and obesity and associated factors in school children and adolescents in a medium-sized Brazilian city. 25(6), 822-829.

[19] Shields, M. (2006). Overweight and obesity among children 
and youth. Health Reports. 17(3),27-42.

[20] Goran, M.I., Reynolds, K.D., Lindquist, C.H. (1999). Role of physical activity in the prevention of obesity in children. International Journal of Obesity and Related Metabolic Disorders, 23 Suppl 3:18-33.

[21] Nemet, D., Barkan, S., Epstein, Y., Friedland, O., Kowen, G., Eliakim, A. (2005). Short- and long-term beneficial effects of a combined dietary-behavioral-physical activity intervention for the treatment of childhood obesity, 115(4), 443-449.

[22] Figueroa-Colon, R., Franklin, F.A., Lee, J.Y., Aldridge, R., Alexander, L. (1997). Prevalence of obesity with increased blood pressure in elementary school-aged children. Suthern Medical Journal, 90(8), 806-813.

[23] Eliakim, A., Kaven, G., Berger, I., Friedland, O., Wolach, B., Nemet, D. (2002). The effect of a combined intervention on body mass index and fitness in obese children and adolescents - a clinical experience. European Journal of Pediatrics, 161(8), 449-454.

[24] Andersen, R.E., Crespo, C.J., Bartlett, S.J., Cheskin, L.J., Pratt, M. (1998). Relationship of physical activity and television watching with body weight and level of fatness among children: results from the Third National Health and Nutrition Examination Survey. JAMA Mar 25;279(12), 938-942.

[25] Kipping, R.R., Jago, R., Lawlor, D.A. (2008). Obesity in children. Part 2: Prevention and management. BMJ, 22;337:a1848. doi: 10.1136/bmj.a1848. 